\title{
An improved automated method for the measurement of red cell 2,3-diphosphoglycerate
}

\author{
YVONNE PURCELL AND B. BROZOVIĆ \\ From the Department of Haematology, St. Bartholomew's Hospital, London EC1A 7BE
}

SYNOPSIS A modified automated colorimetric micromethod for the determination of red cell 2,3diphosphoglycerate (2,3-DPG) adapted from that of Grisolia et al (1969) is described. In the modified method, ethylenediaminetetra-acetic acid (EDTA) is not used and consequently concentrations of several reagents are changed.

During the development of the method it was found that the presence of EDTA, either in the $\stackrel{\triangle}{\perp}$ blood or in reagents, consistently reduced the measured value of $2,3-\mathrm{DPG}$ by $15 \%$. This effect of $\frac{\mathrm{O}}{3}$ EDTA, not previously recognized, is independent of the EDTA concentration within the range of 5 to $50 \mathrm{mmol} / \mathrm{l}$ and is at present unexplained.

In normal subjects (41 men and 30 women) the mean red cell 2,3-DPG was $14.5 \mathrm{~mol} / \mathrm{g}$ haemoglobin (range 12.1-18.1 mol/g haemoglobin). There was no significant difference in 2,3-DPG concentrations between male and female subjects.

Since the first description of an automated method for measuring 2,3-diphosphoglycerate (2,3-DPG) in the blood (Grisolia et al, 1969) several modifications have been published (Atkinson, 1972; Powell et al 1972; Lappin et al, 1973). These methods depend on the effect of 2,3-DPG on the rate of conversion of 3-phosphoglycerate (3-PG) to 2-phosphoglycerate (2-PG) in the presence of phosphoglyceromutase (PGM). The 2-PG formed is converted to pyruvate which is measured colorimetrically. Alternatively, pyruvate is further converted to lactate and the oxidation of NADH is determined fluorometrically (Prins and Loos, 1970).

Although the method of Grisolia et al (1969) is a simple one we found it difficult to use because of the unstable baseline, instability when assaying samples for more than an hour, and because of considerable between-batch variations. In addition, we have found that the ethylenediaminetetra-acetic acid (EDTA) used either in reagents or as anticoagulant affected the absolute values of 2,3-DPG measured. In this report the ways of improving the reliability of the method are described, the means of controlling variation between batches is presented, and the effect of EDTA on 2,3-DPG assay is discussed. The normal range for 2,3-DPG concentration in blood is also presented.

Received for publication 13 April 1976

\section{Material and methods}

The subjects studied comprised 41 men and 30 women, aged 18 to 54 years. All subjects were healthy, with normal haemoglobin concentration (higher than $13.5 \mathrm{~g} / \mathrm{dl}$ for men and $11.5 \mathrm{~g} / \mathrm{dl}$ for women), serum iron and iron binding capacity, serum and red cell folate, and serum vitamin $\mathbf{B}_{12}$ concentrations.

Venous blood was collected in plastic tubes containing heparin or sequestrene; $50 \mu$ l of blood was dispensed with a precision pipette (Medical Laboratory Automation, Inc) into $4.95 \mathrm{ml}$ water, and the solution was stored at $-20^{\circ} \mathrm{C}$. Before being assayed samples were further diluted with a diluter (Hook and Tucker Auto-Diluter Mk II, Chem Lab Instruments Ltd), the final dilution being 1 in 400 .

A Technicon AutoAnalyzer system, comprising sampler II, proportioning pump (2 speed), single dialyzer, colorimeter fitted with a $15 \mathrm{~mm}$ tubular flow cell and $530 \mathrm{~nm}$ filters, and a recorder with a range expander, was used. The manifold was as described by Grisolia et al (1969) with 30 samples per hour and sample to wash ratio 1:1.

Chemicals were purchased from Hopkin and Williams Ltd (analytical grade) and from Sigma Chemical Co. The pyruvic kinase (PK), enolase, and PGM used were prepared in the laboratory according to the methods of Kornberg and Pricer (1951), 
Grisolia et al (1968), and de la Morena et al (1968), respectively. 3-PG was purified to remove contaminating traces of 2,3-DPG according to Grisolia et al (1969).

Reagents were: sodium hydroxide $(0.05 \mathrm{~mol} / \mathrm{l})$; 2-4-dinitrophenylhydrazine $(50 \mathrm{mg}$ dissolved in 100 $\mathrm{ml}$ of $1 \mathrm{~mol} / 1 \mathrm{HCl}$, volume brought up to $400 \mathrm{ml}$ and the solution filtered through Whatman No. 1 filter paper); substrate solution containing $200 \mathrm{ml} 0.2$ mol/l 3-PG, $10 \mathrm{mmol}$ ADP (disodium salt), $30 \mathrm{ml}$ $0.1 \mathrm{~mol} / 1 \mathrm{MgCl}$, and $400 \mathrm{ml} 1.0 \mathrm{mmol} / 1 \mathrm{Tris}-\mathrm{PO}_{4}$ buffer, $\mathrm{pH} 7 \cdot 3$, per litre; enzyme mixture containing 6700 IU PGM, 7000 IU enolase, 23000 IU PK, and $0.5 \mathrm{~g}$ bovine serum albumin per litre. Immediately before use, $4 \mathrm{ml}$ of the enzyme mixture was added to $80 \mathrm{ml}$ substrate solution and the total volume was made up to $160 \mathrm{ml}$ with water. During the assay the enzyme-substrate mixture was kept in an ice-bath. All solutions contained a few drops of $25 \%$ Brij- 35 .

A standard solution of 2,3-DPG containing 600 $\mu \mathrm{mol} / \mathrm{l}$ pentacyclohexylammonium salt was prepared and frozen in $1.2 \mathrm{ml}$ aliquots. One aliquot was used for each assay, dilutions being made to give concentrations ranging from 3.75 to $10 \mu \mathrm{mol} / 1$.

Recorded peak heights were measured in millimetres, and the results were calculated from the calibration curve using a programmed Olivetti P-203 computer.

The manual method for measuring 2,3-DPG of Rose and Liebowitz (1970) was used as described in Sigma Technical Bulletin No. 665. In this method 2,3-DPG is quantitatively converted to the monophosphoglycerate and inorganic phosphate in the presence of PGM, phosphoglycolic acid, and magnesium. Inorganic phosphate is then determined colorimetrically. A standard curve for this reaction is established by measuring varying concentrations of potassium dihydrogen orthophosphate.

\section{VALIDATION OF THE AUTOMATED METHOD}

(a) Within-batch variation

This was determined by calculating the coefficient of variation for each of four blood samples with 2,3DPG concentrations ranging from 1.69 to 3.79 $\mu \mathrm{mol} / \mathrm{l}$ whole blood and four solutions of 2,3-DPG with concentrations ranging from 1.8 to $15.0 \mu \mathrm{mol} / \mathrm{l}$. The mean coefficient of variation for blood samples and 2,3-DPG solutions were 2.09 and $2.73 \%$, respectively.

\section{(b) Between-batch variation}

This was determined by calculating the coefficient of variation of a 'control' sample $(5 \mathrm{ml}$ heparinized blood diluted $1: 100$, dispensed in $4 \mathrm{ml}$ aliquots and stored at $-20^{\circ} \mathrm{C}$ ).

First the control sample was assayed four to six times within each of 15 consecutive batches and the mean 2,3-DPG was calculated. Subsequently the control sample was assayed four to six times within each batch; the mean was calculated and was compared with the previously determined mean (fig 1).

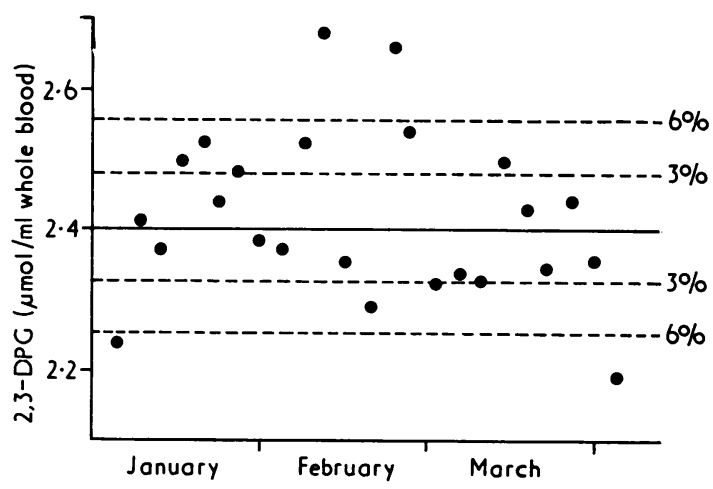

Fig 1 Plot of 2,3-DPG values obtained for the control sample. Each point represents the mean of four to six determinations within one batch. The solid line represents the assigned 2,3-DPG concentration of the sample, $2 \cdot 4$ $\mu \mathrm{mol} / \mathrm{ml}$ whole blood. The between-batch variation was considered (a) unacceptable if greater than $6 \%,(b)$ acceptable, but appropriately corrected, if between 3 and $6 \%$, and acceptable without any correction if less than $3 \%$.

The coefficient of variation calculated from determinations over a period of nine months was $5.74 \%$. Batches where the mean concentration of the control sample varied by more than $6 \%$, an arbitrarily selected figure, from the established mean were repeated. In batches where the mean concentration varied between $3 \%$ and $6 \%$, the value of each sample was corrected accordingly. The batches in which the variation of the mean of the control sample was less than $3 \%$ were accepted without correction.

\section{(c) Recovery}

The recovery of 2,3-DPG added to the sample was determined by mixing equal volumes of a sample and standard solutions. For this 2,3-DPG solutions of 3.75 and $7.5 \mu \mathrm{mol} / 1$ were added to four different blood samples with concentrations ranging from 3.7 to $9.88 \mu \mathrm{mol} / \mathrm{l}$. The measurement of $2,3-\mathrm{DPG}$ concentration in each sample was carried out five times; the mean was calculated and expressed as a percentage of the expected value. The mean recovery was $103 \%$ (range $99-106 \%$ ).

(d) Comparison of results by the manual method 2,3-DPG concentration was determined by both the 
manual and the automated methods in 16 blood samples collected in heparin. Although the correlation between the two methods was good $(r=0.98)$, values obtained manually averaged $85 \%$ of those obtained by the automated method (fig 2). The same difference was found when several 2,3-DPG standard solutions ranging from 0.5 to $6.0 \mathrm{mmol} / 1$ were assayed.

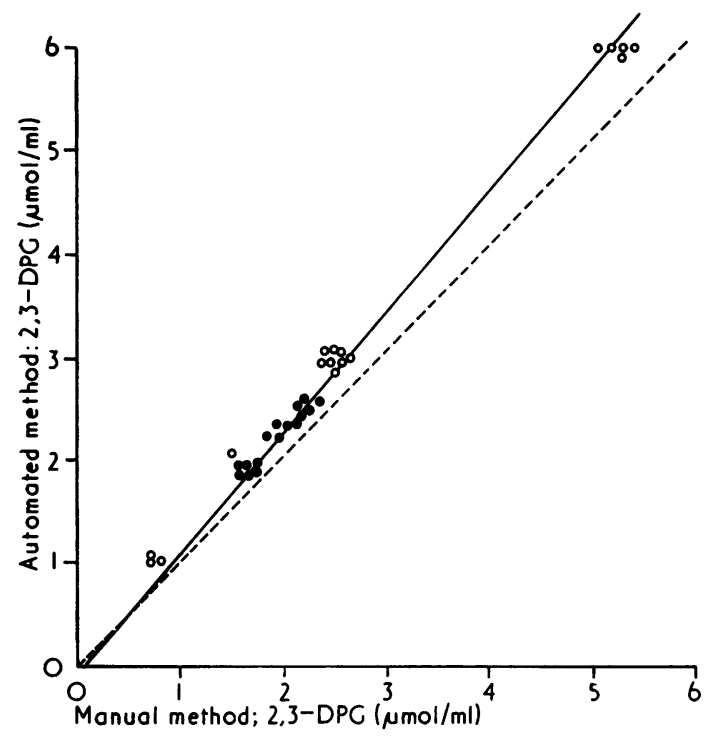

Fig 2 Correlation of 2,3-DPG values measured by the manual method and by the automated method; o blood samples; $\bigcirc$ standards. The continuous line represents the regression line: $y=0.886 x+0.076, r=0.98$ $(\mathrm{P}<0.001)$. The broken line represents ideal correlation.

\section{EFFECT OF EDTA UPON MEASUREMENT OF}

2,3-DPG

2,3-DPG in aliquots of the same blood taken into heparin and EDTA (dipotassium salt) were consistently different, the values of the samples with EDTA being on average $85 \%$ (range $78 \cdot 1-92.2 \%$ ) that of the samples with heparin (table). A similar difference was found when heparin and EDTA were added to 2,3-DPG solutions; the value in the sample with EDTA was $85.2 \%$ (range $83.9-86.9 \%$ ) of that of the sample with heparin. This difference was not dependent upon the concentration of EDTA in the blood sample, as the same values were obtained within the range 5 to $50 \mathrm{mmol} / \mathrm{l}$ of EDTA.

In contrast to the findings with the automated method, there was no difference in 2,3-DPG concentration obtained by the manual method when aliquots of 2,3-DPG solutions and of the same blood taken into either heparin or EDTA were measured.

\begin{tabular}{|c|c|c|c|c|}
\hline \multirow{2}{*}{$\begin{array}{l}\text { Blood } \\
\text { samples } \\
\text { (no.) }\end{array}$} & \multirow[t]{2}{*}{$\begin{array}{l}\text { Number of } \\
\text { aliquots }\end{array}$} & \multirow{2}{*}{$\begin{array}{l}\text { Mean 2,3-DPG in } \\
\text { heparinized blood } \\
(\mu \mathrm{mol} / \mathrm{ml})\end{array}$} & \multicolumn{2}{|c|}{$\begin{array}{l}\text { Mean 2,3-DPG in } \\
\text { sequestrene blood }\end{array}$} \\
\hline & & & $\mu \mathrm{mol} / \mathrm{ml}$ & $\begin{array}{l}\text { Per cent of value } \\
\text { for heparinized } \\
\text { blood }\end{array}$ \\
\hline $\begin{array}{l}1 \\
2 \\
3 \\
4 \\
5 \\
6^{1} \\
7^{2}\end{array}$ & $\begin{array}{l}8 \\
2 \\
2 \\
1 \\
4 \\
1 \\
3\end{array}$ & $\begin{array}{l}1.33 \\
2 \cdot 14 \\
2.01 \\
2.42 \\
2.60 \\
1.35 \\
2.05\end{array}$ & $\begin{array}{l}1.08 \\
1.88 \\
1.73 \\
2.15 \\
2.03 \\
1.15 \\
1.90\end{array}$ & $\begin{array}{r}81 \cdot 2 \\
87.8 \\
86.3 \\
88 \cdot 8 \\
78 \cdot 1 \\
86.0 \\
92 \cdot 2 \\
\overline{\mathbf{x}}=85.8\end{array}$ \\
\hline
\end{tabular}

${ }^{1}$ Fresh blood sample (other samples were diluted and stored at $-20^{\circ} \mathrm{C}$ N before being assayed)

'Blood sample was kept at $4^{\circ} \mathrm{C}$ for six days before dilution

NORMAL RANGE OF 2,3-DPG CONCENTRATIONS

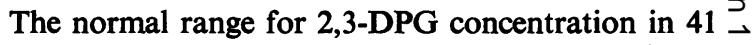
men and 30 women was from $12 \cdot 1$ to $18 \cdot 1 \mu \mathrm{mol} / \mathrm{g} \mathrm{Hb}$ and from 12.7 to $18.0 \mu \mathrm{mol} / \mathrm{g} \mathrm{Hb}$ respectively, mean concentration 14.4 and $14.6 \mu \mathrm{mol} / \mathrm{g} \mathrm{Hb}$, respectively. The difference in 2,3-DPG concentrations between males and females was not significant $(P>0 \cdot 1$, Student's $t$ test) and therefore the combined range of 2,3-DPG concentrations in all normal subjects was . 12.0 to $18 \cdot 1$, with a mean of $14.5 \mu \mathrm{mol} / \mathrm{g} \mathrm{Hb}$.

\section{Discussion}

The main difficulty encountered when measuring red $\stackrel{\varnothing}{\varnothing}$ cell 2,3-DPG with the original method of Grisolia $e t \vec{\overrightarrow{ }}$ al (1969) was the precipitation of brown magnesium 3 hydroxide. Although EDTA is present in the reaction mixture, it does not prevent the formation of magnesium hydroxide at alkaline $\mathrm{pH}$ attained when sodium hydroxide enters the stream of reagents. The precipitate is not a heavy one, but in our laboratory it affected the recordings to such a degree as to make them unreadable. We were able to avoid precipitation of magnesium hydroxide on the one hand by reducing its concentration, and on the other hand by increasing the concentration of EDTA, but both $\frac{7}{0}$ procedures impeded considerably the rate of pyruvate formation. Therefore we decided to $N$ abandon the use of EDTA and at the same time $N$ reduce the concentration of magnesium 10 times. $N$ This prevented the formation of precipitate and $\omega$ ensured smooth and stable recorder tracings. In

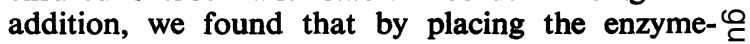
substrate mixture into ice we were able to extend the duration of assay for up to three hours.

It is generally accepted that the main role of EDTA ${ }_{0}^{\circ}$ is to chelate heavy metals which may inhibit the $\frac{\vec{D}}{\mathbb{D}}$ enzymatic reactions. Therefore the exclusion of $\frac{\rho}{\mathbb{D}}$ 
EDTA from the reagents compelled us to investigate whether EDTA, used as an anticoagulant in blood containers, affects the rate of pyruvate formation. Contrary to expectations the presence of EDTA in the blood reduced the overall rate of reaction by $15 \%$ compared to the rate measured in the heparinized blood. This difference was also found in solutions of pure 2,3-DPG to which either EDTA or heparin were added in concentrations comparable to those found in samples of blood. It is not likely that EDTA reduces the rate of reaction entirely by chelating magnesium as the effect of EDTA was the same when its concentration varied from 5 to 50 $\mathrm{mmol} / \mathrm{l}$, although there was a further reduction in the reaction rate when the concentration of EDTA exceeded $50 \mathrm{mmol} / 1$. At present it is possible only to speculate that this effect of EDTA is due to chelation of a metal(s) other than magnesium required for the optimum rate of pyruvate formation. It is of interest that all previously published methods for measuring 2,3-DPG reagents make use of varying concentrations of EDTA.

At present there is no satisfactory explanation for a considerable between-batch variability, particularly in view of the fact that each sample within a bad batch was affected proportionally to the 'control', and that the within-batch reproducibility remained very good. The latter finding made it possible to correct all the values in a bad batch in proportion to the difference between the mean measured and previously determined 'control' values. Although there is no reason why batches with even a large difference between these two values could not be corrected, we chose to correct only the values in batches in which the difference was between $3 \%$ and $6 \%$. We felt that a smaller difference does not require correction and a larger one, perhaps, needs to be repeated. The use of a classical approach to quality control by discarding batches when the variation of the mean for 'control' samples exceeds the predetermined tolerance interval would increase the number of batches to such an extent as to make it unworkable.

The mean and range of red cell 2,3-DPG for 71 normal men and women was $14.5 \mu \mathrm{mol} / \mathrm{g} \mathrm{Hb}$ and 12.1 to $18.1 \mathrm{~mol} / \mathrm{g} \mathrm{Hb}$. These values are in close agreement with those reported by Eaton et al (1970), Atkinson (1972), and Dickerman et al (1973). No significant difference between red cell 2,3-DPG in men and women was found. This is in accordance with reports by Hellerstein et al (1970) but at variance with other reports (Eaton and Brewer, 1968; Hjelm, 1969; Dickerman et al, 1973).

It is a pleasure to thank Professor D. L. Mollin for his unstinted interest during the course of this investigation. This work was in part supported by a grant to Professor Mollin from the Wellcome Trust.

\section{References}

Atkinson, K. F. (1972). Modified automated determination of 2,3-diphosphoglycerate in whole blood. Clin. Chem., 18, 1001-1004.

de la Morena, E., Santos, I., and Grisolia, S. (1968). Homogenous crystalline phosphoglycerate phosphomutase of high activity. A simple method for lysis of yeast. Biochim. Biophys. Acta (Amst.), 151, 526-528.

Dickerman, J. D., Ostrea, E. M., Jr., and Zinkham, W. H. (1973). In vivo aging of transfused erythrocytes and 2,3diphosphoglycerate levels. Blood, 42, 9-15.

Eaton, J. W. and Brewer, G. J. (1968). The relationship between red cell 2,3-diphosphoglycerate and levels of hemoglobin in the human. Proc. nat. Acad. Sci. (Wash.), 61, 756-760.

Eaton, J. W., Brewer, G. J., Shultz, J. S., and Sing, C. F. (1970). Variation in 2,3-diphosphoglycerate and ATP levels in human erythrocytes and effects on oxygen transport. Advanc. Exp. med. Biol., 6, 21-38.

Grisolia, S., Bogart, D. B., and Torralba, A. (1968). A simple and rapid procedure for the preparation of phosphopyruvate hydratase free from phosphoglycerate phosphomutase and pyruvate kinase. Biochim. biophys. Acta (Amst.), 151, 298-299.

Grisolia, S., Moore, K., Luque, J., and Grady, H. (1969). Automatic procedure for the microestimation of 2,3diphosphoglycerate. Analyt. Biochem., 31, 235-245.

Hellerstein, S., Grady, H., and Grisolia, S. (1970). Normal values of red cell 2,3-diphosphoglycerate by a simplified automated method. J. Lab. clin. Med., 76, 171-174.

Hjelm, M. (1969). The content of 2,3-diphosphoglycerate and some other phosphocompounds in human erythrocytes from healthy adults and subjects with different types of anaemia. Forsvarsmedicin, 5, 219-226.

Kornberg, A. and Pricer, W. E., Jr. (1951). Enzymatic phosphorylation of adenosine and 2,6-diaminopurine riboside. J. biol. Chem., 193, 481-495.

Lappin, T. R., Elder, G. E., and Coulter, C. D. (1973). Automated colorimetric determination of 2,3-diphosphoglycerate. Clin. chim. Acta, 44, 349-356.

Powell, J. B., Emery, C. E., and Peyton, G. A. (1972). Automated procedure for assay of 2,3-diphosphoglycerate in red cells by measuring enzymatically released inorganic phosphorus. Clin. Chem., 18, 1318-1322.

Prins, H. K. and Loos, J. A. (1970). Determination of energy-rich phosphate, 2,3-diphosphoglycerate, lactate and glutathione in small amounts of blood cells. (Technicon International Congress 1969). Advanc. Automat. Analysis, 1 285-292.

Rose, Z. B. and Liebowitz, J. (1970). 2,3-diphosphoglycerate phosphatase from human erythrocytes: general properties and activation by anions. J. biol. Chem., 245, 3232-3251. 